\title{
Stock market regulations and international financial integration: the case of Spain
}

\author{
J. I. PEÑA ${ }^{1}$ and E. RUIZ ${ }^{2}$ \\ ${ }^{1}$ Departamento de Economía de la Empresa and ${ }^{2}$ Departamento de Estadística y \\ Econometría, Universidad Carlos III de Madrid, C/ Madrid 126-128, 28903 Getafe, \\ Madrid, Spain
}

International financial integration effects on the Spanish stock market are studied, both for the conditional mean and conditional variance. New institutional regulations in Spain are taken into account and their efficiency consequences are addressed. Results suggest an increasing international integration but nontrivial opportunities for financial diversification may still be relevant.

Keywords: financial integration, market reforms, stochastic volatility

\section{INTRODUCTION}

This paper addresses the consequences of the Spanish Stock Exchange Reform on the market's degree of international financial integration. A sharp change in the regulated Spanish Stock Exchange (SSE) occurred in 1988 due to the Stock Market Reform Law (SMRL). The main points of this law were as follows. First the Official Stock Market Agents, previously appointed by the Government, were replaced by private brokers and dealers. A new trading system was established, the Computer Assisted Trading System (CATS), which is opened from 11:00am to $5: 00 \mathrm{pm}$. This new system was the cause of the practical termination of the traditional open outcry trading process. The CATS became fully operational in the first quarter of 1990 . However, some floor trading remained for small stocks from 10:00am to $12: 15 \mathrm{pm}$. Second, the previously regulated brokerage fees were liberalized, and the resulting commission price war among Spain's brokers has led to up to $0.12 \%$ commission for typical market transactions. Also, the Comisión Nacional del Mercado de Valores (CNMV) was created. This commission is the Spanish equivalent of the United States Securities and Exchange Commission. Finally, a new settlement and clearing service was created and was operational at the same time as CATS; cash balances are cleared in $48 \mathrm{~h}$. Before SMRL, cash balances of operations from one given week (Monday to Friday) were cleared on the next week's Friday. The new settlement period is $T+10$, and previously was $T+30$. In April 1993 the CNMV opened its 'Servicio de Compensación y Liquidación', the securities settlement and clearing service, 
aimed at expediting the settlement period. In 1995 the settlement period was reduced further to $T+5$.

Another important change also took place around those dates. The six main Spanish stocks (in terms of market value) become listed securities on the New York Stock Exchange (NYSE) in the period 6/87 to 5/89. Those firms' market value (in Spain) amounted to almost $50 \%$ of total value. ${ }^{1}$

It is well known that the USA and Japan account for approximately $80 \%$ of the world's market value of exchange-listed securities. Important European markets are the London Stock Exchange (LSE) and Frankfurt Stock Exchange (FSE). However, although the total market value of the equities listed on the Tokyo Stock Exchange (TSE) was approximately 15 points larger than on the NYSE in the late 1980s and early 1990s, some authors (for instance, Eun and Shim (1989), Becker et al. (1990) and Hamao et al. (1990)) suggest that the US market is the essential leader in price movements and the most influential market in the world. Similar results for the Spanish market are shown in Espitia and Manzano and Mateos (1991), Santamaría (1991) and Peña (1992a,b) using different models.

The institutional changes mentioned before might affect the time series properties of the security prices in the SSE. In particular, such changes may have empirically testable implications for the variances, autocorrelations and cross-correlations of returns of individual stocks and portfolios as well as of the Spanish Market Index (IGBM). ${ }^{2}$

We could expect that, after SMRL, the SSE should provide more efficiently valued securities and therefore autocorrelations, both in individual securities and in the Market Index, should decrease. For arbitrage reasons, the listing of major Spanish stocks in NYSE and other markets might increase the interdependence between domestic and international securities markets, both in mean returns and in volatility.

Thus, this study focuses on the influences of four main stock markets: New York Stock Exchange (represented by Dow-Jones Index, DJ), Tokyo Stock Exchange (Nikkei index, NIK), London Stock Exchange (FT100 index, FTD) and Frankfurt Stock Exchange (Commerzbank index, COM) over a small market (about 1\% of the world's market value), the Spanish Stock Exchange, using daily data. The paper is organized as follows. In Section 2 we present the econometric framework. Section 3 contains the empirical results and Section 4 some tentative conclusions.

\footnotetext{
${ }^{1}$ The firms, their market value in Spain and date of listing in NYSE are: Telefónica (11\%) 6/87, Banco Santander (6\%) 7/87, BCH (7\%) 7/87 (formerly separate Banks Central and Hispano), ENDESA (10\%) $5 / 88$, BBV (7\%) $10 / 88$, Repsol (8\%) $5 / 89$. What is traded is not the stock itself but American: Depository Receipts (ADR) which are financial assets issued by a US bank, and represent indirect ownership of a certain number of shares that are held on deposit in a bank in the company's home country. Telefónica, BBV and Banco Santander are also listed in the stock exchanges of Tokyo, London and Frankfurt.

${ }^{2}$ As the Spanish Market Index we use the Madrid Stock Exchange's General Index (IGBM). This index is made up each year of 72 companies and represents about $80-85 \%$ of the total capitalization of the market, excluding foreign stocks. It accounts for dividends and stock splits, and is a market value weighted index.
} 


\section{ECONOMETRIC FRAMEWORK}

To model the dynamic relationships between the Spanish market's returns and the other international markets' returns considered in this paper, a singleequation econometric model is fitted. We define $R_{t}$, the daily return for the SSE index, as $R_{t}=\ln \left(x_{t}-\ln \left(x_{t-1}\right)\right.$, where $x_{t}$ is the spot price. The proposed model for SSE returns is ${ }^{3}$

$$
R_{t}=\sum_{i=1}^{4} \sum_{j=0}^{J} \delta_{i j} Z_{i t-j}+\sum_{k=1}^{q} \theta_{k} e_{t-k}
$$

where $Z_{i t}, i=1, \ldots, 4$, are foreign stock markets returns for DJ, NIK, FTD and COM, respectively, and $e_{t}$ is a zero mean, uncorrelated noise process with constant unconditional variance. The reason for allowing for serial correlation in the SSE index returns stems from the possible 'Fisher effect' (nonsynchronous trading) and other frictions in the trading process, as discussed in Scholes and Williams (1977) and Lo and MacKinlay (1990). We estimate model (1) for the whole sample and for several subsamples by quasi-maximum likelihood (QML), treating $e_{t}$ as if it were Gaussian. To take into account the possible heteroscedasticity of the disturbances $e_{t}$, the covariance matrix of the estimates has been computed using White's (1980) heteroscedasticity-consistent covariance matrix.

Then, we consider univariate stochastic volatility models to represent the possibly time-varying conditional variances of the residuals $e_{t}$. We treat the volatility as an unobservable variate at time $t-1$, allowing unexpected news at time $t$ to have effects on the volatility at time $t$. In this vein, Taylor (1986) proposed the stochastic volatility (SV) models where the logarithm of the volatility is modelled as a linear process, for example, an autoregression. The simplest stationary SV model is given by

$$
\begin{gathered}
e_{t}=\sigma_{\star} \varepsilon_{t} \sigma_{t} \\
\log \left(\sigma_{t}^{2}\right)=\phi \log \left(\sigma_{t-1}^{2}\right)+\eta_{t}
\end{gathered}
$$

where $\sigma_{\star}$ is a scale parameter, $|\phi|<1$ to guarantee second-order stationarity and $\epsilon_{t}$ and $\eta_{t}$ are mutually uncorrelated Gaussian white noise processes with variances 1 and $\sigma^{2}$, respectively. Model (2) will be denoted by ARV(1).

The specification of the volatility in (2b) may not be the most appropriate when dealing with stock returns because often the response of volatility to positive movements in prices is smaller than the response to negative movements; see, for example, Black (1976), Christie (1982) and Nelson (1991). This asymmetry is known as the 'leverage' effect. To allow for asymmetric

\footnotetext{
${ }^{3}$ We are assuming some kind of exogeneity for the variables $Z$ (foreign stock market returns) in our model. The reasons for that are the small size of SSE, and the growing influence of foreign investment in it, specially after 1986 . Foreign investors are the owners of more than $20 \%$ of total listed equity. On the other hand, holdings of foreign stocks in Spanish portfolios are negligible. Also, Granger's causality tests (available on request) do not show any influence of the SSE on any other of the markets considered in this study. We also tried models with dummy day-of-the-week variables, but these variables were not statistically significant at any conventional level.
} 
effects in volatility, we can extend model (2) by including past returns in the volatility equation, as follows

$$
\log \left(\sigma_{t}^{2}\right)=\phi \log \left(\sigma_{t-1}^{2}\right)+\sum_{i+1}^{r} \alpha_{i} \frac{e_{t-i}}{\sigma_{t-i}}+\eta_{t}
$$

where $|\phi|<1$ to guarantee second-order stationarity.

Also, model (2) may be extended allowing for day-of-the-week effects often present in volatility, with Mondays having greater unconditional variance than the rest of the weekdays; see, for example, Hsieh (1988) and Baillie and Bollerslev (1989). In the context of SV models this effect can be easily incorporated by having two different scale constants, i.e. in equation (2a), $\sigma_{*}=\sigma_{(1)}$ for Mondays and $\sigma_{*}=\sigma_{(2)}$ for all the other days of the week.

SV models have the difficulty that they are not conditionally Gaussian; see, for example, Ruiz (1994). However, their estimation can be carried out by a QML method proposed independently by Nelson (1988) and Harvey et al. (1994) and this is the approach we are adopting in this paper. The QML estimation method is based on the following transformation of model (2):

$$
\begin{aligned}
& \log \left(e^{2}\right)=\mu+\log \left(\sigma_{t}^{2}\right)+\xi_{t} \\
& \log \left(\sigma_{t}^{2}\right)=\phi \log \left(\sigma_{t-1}^{2}\right)+\eta_{t}
\end{aligned}
$$

where $\mu=\log \left(\sigma_{*}^{2}\right)+E\left(\xi_{t}\right)$ and $\xi_{t}=\log \left(\varepsilon^{2}\right)-E\left[\log \left(\varepsilon^{2}\right)\right]$. The parameters $\phi, \sigma^{2}{ }_{\eta}$ and $\sigma_{\xi}^{2}$, where $\sigma_{\xi}^{2}$ is the variance of $\xi_{t}$, can be estimated by QML by treating $\eta_{t}$ and $\xi_{t}$ as though they were normal and maximizing the prediction error decomposition form of the Gaussian likelihood obtained via the Kalman filter. The asymptotic distribution of the QML estimator can be obtained by applying the theory in Dunsmuir (1979); see Ruiz (1994). The parameter $\sigma_{\star}$ can be estimated as proposed by Harvey and Shephard (1993) by using the sample variance of the heteroscedasticity corrected observations. Under normality of $\varepsilon_{t}$ and for large sample size, $T$, the variance of this estimator is $4.93 \sigma^{4} * / T$. Once the parameters of model (2) have been estimated, it is possible to apply the Kalman filter to model (4) to obtain minimum mean square linear one-step-ahead estimates of the volatility, $\hat{\sigma}_{t / t-1}$, and a fixed-interval smoothing algorithm to obtain estimates of the volatility using the information in the whole sample, $\hat{\sigma}_{t / T}$; see, for example, Harvey et al. (1994).

Finally, we also consider the possible relationships between the Spanish market volatility and volatilities in the other markets by means of analysing the cross-correlations between the estimated volatilities in the different markets.

\section{EMPIRICAL RESULTS}

\subsection{The data}

The data consists of the daily closing (close-to-close) returns for all the indexes from 1 January 1987 to 2 October 1992, and was obtained from the Studies 
Table 1. Features of the stock markets in the study

\begin{tabular}{llcll}
\hline Market & Index name & No. of stocks & Weights & Corrections $^{a}$ \\
\hline New York & Dow Jones & 30 & - & AC,S \\
London & FT100 & 100 & Market value & AC \\
Madrid & IGBM & 72 & Market value & AC,D \\
Frankfurt & CommerzBank & 60 & Market value & AC \\
Tokyo & Nikkei & 225 & - & AC,S \\
\hline
\end{tabular}

${ }^{a} \mathrm{AC}=$ New equity issues (not first time issues);

$S=$ Stock splits;

$\mathrm{D}=$ Dividends.

Department of the Madrid Stock Exchange. The sample size is 1352. Table 1 shows some index features, such as the index name, the number of stocks and corrections for stocks splits, market value or new issues. European indexes are market value weighted, in contrast with the American and Japanese indexes which are simple price indexes. All the indexes allow for stock splits and new issues, but only the Madrid index takes into account dividends. ${ }^{4}$

Table 2 shows opening and closing hours in Madrid time, as well as the relative market value of each stock exchange as a percentage of world market value. ${ }^{5}$ Note that there are time intervals when New York, Madrid and London overlap. However, European markets close before New York closing value is known. Also Tokyo's closing values are known before any market opens. Note also that, on a given day, the agents in the Madrid market know all the closing values before Madrid itself closes, but only the opening value for New York. Thus, in addition to the usual close-to-close return, we also compute the closeto-open (CTO) return for New York.

Data analysis and the changes in the institutional framework mentioned in the Introduction, suggest four different regimes in our sample. The first one goes

Table 2. Opening and closing times and percentage of world market value

\begin{tabular}{lrrr}
\hline Market & Open $^{\mathrm{a}}$ & Close $^{\mathrm{a}}$ & World market value (\%) \\
\hline New York & $14: 30$ & $21: 00$ & 29.4 \\
London & $9: 00$ & $15: 30$ & 8.9 \\
Madrid & $11: 00$ & $17: 00$ & 1.1 \\
Frankfurt & $11: 30$ & $13: 30$ & 2.8 \\
Tokyo & $1: 00$ & $7: 00$ & 46.3 \\
\hline
\end{tabular}

a Hours of open and close are in Madrid time.

${ }^{4}$ The procedure is as follows: on 31 December an estimation of the expected net dividends each stock will pay is computed. This amount, expressed as percentage of par value, is divided by 365 . The resulting amount multiplied by the number of days elapsed since the beginning of the year is subtracted daily from the market price.

${ }^{5}$ There are some arguments about the real significance of Tokyo Stock Exchange figures. Some studies allowing for the effect of cross-participation between firms, reduce its market value about 40\%; see French and Poterba (1990). 
from $1 / 1 / 87$ to the big crash on 19th of October 1987 (190 data points). The second one goes from this day to the beginning of the Continuous Market (MC) $(1 / 4 / 89)$ (334 data points). ${ }^{6}$ The third one is a transition period, lasting for one year approximately (242 data points) where new firms begin to quote their prices in the new system. During the last regime, which consists of 567 observations, the MC is working normally and the main Spain's blue chips are listed on the NYSE.

Table 3 shows several sample moments of the SSE returns multiplied by 100 , obtained using the different subsamples described above. In Table 3 , it is possible to observe that the dynamic properties of the SSE returns change dramatically in each of the regimes considered. It is important to note that the unconditional variance seems to change from one regime to the other. In all regimes the returns have significant excess kurtosis. The first-order autocorrelation decreases in each of the regimes. Also, as seen in the McLeod-Li statistics, $\mathrm{Q}_{2}$, the autocorrelations of the squares are only significant in the second and last subsamples. The excess kurtosis together with the autocorrelations of the squares may be caused by the presence of conditional heteroscedasticity.

We estimate model (1) separately for each of the subsamples given that the possible structural changes may affect both the dynamic behaviour of the series (as we have seen in Table 3) and the relationship with the foreign markets.

\subsection{Estimation of the conditional mean}

First, we estimate the dynamic regression in model (1) by maximizing the Gaussian likelihood. The estimation results are summarized in Table 4 . The table shows the estimated values (and corresponding $t$-values in parentheses) of coefficients for the contemporaneous effects of all four foreign markets, the US and UK market lagged 1 day and the moving average term of lag one. We observe that:

(i) In the first regime, before October 1989 and before MC, no relevant foreign stock market effects are detected, as can be deduced from the non significant parameters and low multiple correlation coefficient, $R^{2}$, value. Note also the high value of the MA(1) parameter. ${ }^{7}$

(ii) In the second regime, influences from New York, Tokyo and London begin to become apparent. These effects are instantaneous or with a one-day lag. The reason for lagged effects might be that the old trading system was only open from 10.00 to 13.00 hours. The coefficient $R^{2}$ increases its value. Note the low value of the MA(1) parameter in comparison with the previous period.

\footnotetext{
${ }^{6}$ To minimize data problems related to the big crash, two weeks of data before and after the crash were deleted.

${ }^{7}$ This result could be seen as evidence against the weak form of the efficient market hypothesis in the Madrid market. However, the results in Peña (1995) suggest a high degree of nonsynchronous trading in Madrid due to the thinness of the market.
} 
(iii) In the transition period, the foreign effects are again detected, albeit somewhat different in magnitude.

(iv) The last period shows a significant effect from New York (close-to-open return CTO) and a mild effect from previous day close-to-close return. Also, less important but still significant effects are found from Tokyo, London and Frankfurt. The MA(1) parameter is the lowest of all periods suggesting

Table 3. Sample moments and related statistics of percentage returns of the Spanish stock market (SSE)

\begin{tabular}{|c|c|c|c|c|}
\hline & $\begin{array}{l}1 / 1 / 87- \\
8 / 10 / 87\end{array}$ & $\begin{array}{l}28 / 10 / 87- \\
1 / 4 / 89\end{array}$ & $\begin{array}{l}2 / 4 / 89 \\
30 / 3 / 90\end{array}$ & $\begin{array}{l}31 / 3 / 90- \\
2 / 10 / 92\end{array}$ \\
\hline Sample size & 189 & 334 & 242 & 567 \\
\hline Mean & 0.2186 & 0.0861 & -0.0608 & -0.0470 \\
\hline Variance & 1.9551 & 0.9260 & 0.4540 & 1.3976 \\
\hline Skewness ${ }^{a}$ & $\begin{array}{l}0.5098 \\
(8.23)\end{array}$ & $\begin{array}{c}0.1170 \\
(0.76)\end{array}$ & $\begin{array}{c}-2.2481 \\
(203.84)\end{array}$ & $\begin{array}{l}-0.0043 \\
(0.0)\end{array}$ \\
\hline Kurtosis $^{b}$ & $\begin{array}{l}5.7013 \\
(57.77)\end{array}$ & $\begin{array}{l}8.2280 \\
(379.75)\end{array}$ & $\begin{array}{c}19.1937 \\
(2644.23)\end{array}$ & $\begin{array}{c}7.7292 \\
(528.38)\end{array}$ \\
\hline $\operatorname{Acf}^{c}$ & & & & \\
\hline$r(1)$ & $\begin{array}{l}0.3563 \\
(24.50)\end{array}$ & $\begin{array}{l}0.1886 \\
(11.95)\end{array}$ & $\begin{array}{l}0.1754 \\
(7.54)\end{array}$ & $\begin{array}{l}0.1400 \\
(11.17)\end{array}$ \\
\hline$r(2)$ & $\begin{array}{l}0.0056 \\
(24.51)\end{array}$ & $\begin{array}{l}0.1469 \\
(19.22)\end{array}$ & $\begin{array}{l}0.0975 \\
(9.88)\end{array}$ & $\begin{array}{c}0.0913 \\
(15.94)\end{array}$ \\
\hline$r(3)$ & $\begin{array}{l}-0.0159 \\
(24.56)\end{array}$ & $\begin{array}{l}-0.1331 \\
(25.21)\end{array}$ & $\begin{array}{l}0.0024 \\
(9.88)\end{array}$ & $\begin{array}{c}0.0206 \\
(16.18)\end{array}$ \\
\hline$r(4)$ & $\begin{array}{l}0.0576 \\
(25.21)\end{array}$ & $\begin{array}{l}-0.0842 \\
(27.62)\end{array}$ & $\begin{array}{l}0.0111 \\
(9.91)\end{array}$ & $\begin{array}{c}0.0193 \\
(16.39)\end{array}$ \\
\hline$r(5)$ & $\begin{array}{l}0.0106 \\
(25.23)\end{array}$ & $\begin{array}{l}-0.1506 \\
(35.33)\end{array}$ & $\begin{array}{c}-0.0127 \\
(9.95)\end{array}$ & $\begin{array}{l}0.0378 \\
(17.21)\end{array}$ \\
\hline $\begin{array}{l}Q(10) \\
\text { Acf squares }\end{array}$ & 32.34 & 50.98 & 17.41 & 24.82 \\
\hline$r_{2}(1)$ & $\begin{array}{l}0.0170 \\
(0.06)\end{array}$ & $\begin{array}{c}0.1202 \\
(4.85)\end{array}$ & $\begin{array}{l}0.0559 \\
(0.77)\end{array}$ & $\begin{array}{l}0.1671 \\
(15.91)\end{array}$ \\
\hline$r_{2}(2)$ & $\begin{array}{l}-0.0340 \\
(0.28)\end{array}$ & $\begin{array}{l}0.1592 \\
(13.39)\end{array}$ & $\begin{array}{c}-0.0144 \\
(0.82)\end{array}$ & $\begin{array}{l}0.1845 \\
(35.35)\end{array}$ \\
\hline$r_{2}(3)$ & $\begin{array}{l}0.1475 \\
(4.52)\end{array}$ & $\begin{array}{c}0.2392 \\
(32.73)\end{array}$ & $\begin{array}{l}0.0026 \\
(0.82)\end{array}$ & $\begin{array}{c}0.0700 \\
(38.15)\end{array}$ \\
\hline$r_{2}(4)$ & $\begin{array}{l}0.0118 \\
(4.55)\end{array}$ & $\begin{array}{c}0.1628 \\
(41.72)\end{array}$ & $\begin{array}{c}-0.0096 \\
(0.84)\end{array}$ & $\begin{array}{l}0.0597 \\
(4019)\end{array}$ \\
\hline$r_{2}(5)$ & $\begin{array}{c}-0.0107 \\
(4.57)\end{array}$ & $\begin{array}{c}0.3657 \\
(87.20)\end{array}$ & $\begin{array}{c}-0.0192 \\
(0.93)\end{array}$ & $\begin{array}{c}0.1869 \\
(60.24)\end{array}$ \\
\hline$Q_{2}(10)$ & 11.69 & 176.03 & 1.42 & 81.42 \\
\hline
\end{tabular}

${ }^{a}$ The statistic in parenthesis has a $\chi_{(1)}^{2}$ distribution under the null of zero skewness.

${ }^{b}$ The statistic in parenthesis has a $\chi_{(1)}^{2}$ distribution under the null of kurtosis $=3$.

' The values in parenthesis in the autocorrelation function (acf) and acf of squares are the BoxLjung statistics. 
an increase in efficiency after MC. The fit is reasonably good, taking into account the simple model we are using. ${ }^{8}$

The empirical results summarized above suggest an increase in the SSE operational efficiency after the Reform as reflected by the decrease in the SSE return's inertia. Also, the joint effects of the Reform and the listing of Spain's blue chips in foreign markets seems to increase the international integration of the SSE.

\subsection{Estimation of volatility}

The objective of this subsection is to analyse the dynamic behaviour of the volatility in the SSE market index by fitting first univariate SV models and then

Table 4. Summary of the estimation results of the dynamic regression model, equation (1)

\begin{tabular}{lcccc}
\hline & Period & & & \\
\cline { 2 - 5 } Variable & $1 / 1 / 87-$ & $28 / 10 / 89-$ & $2 / 4 / 89-$ & $31 / 3 / 90-$ \\
\hline DJD (CTO) & $2 / 10 / 87$ & $1 / 4 / 89$ & $30 / 3 / 90$ & $2 / 10 / 92$ \\
\hline & -0.13 & 0.18 & 0.15 & 0.63 \\
DJD (-1) & $(0.7)$ & $(1.4)$ & $(1.6)$ & $(7.3)$ \\
& 0.24 & 0.31 & 0.23 & 0.08 \\
NIK & $(2.7)$ & $(5.8)$ & $(6.4)$ & $(1.8)$ \\
& -0.08 & 0.05 & 0.15 & 0.06 \\
FTD & $(0.9)$ & $(0.5)$ & $(3.7)$ & $(2.6)$ \\
& 0.07 & -0.09 & 0.02 & 0.24 \\
FTD (-1) & $(0.6)$ & $(1.1)$ & $(0.6)$ & $(5.2)$ \\
& 0.06 & 0.12 & 0.01 & -0.08 \\
COM & $(0.6)$ & $(1.8)$ & $(0.3)$ & $(1.6)$ \\
& -0.15 & 0.15 & 0.14 & 0.28 \\
MA (1) & $(1.5)$ & $(2.3)$ & $(4.3)$ & $(6.7)$ \\
& 0.36 & 0.15 & 0.21 & 0.12 \\
Adjusted $R^{2}$ & $(5.0)$ & $(2.2)$ & $(3.6)$ & $(2.4)$ \\
\hline
\end{tabular}

a Description of variables used:

DJD $(-1)$ : Dow Jones returns at time $t-1$

$D J D$ (CTO): Dow Jones returns (close-open)

NIK: Nikkei returns

FTD: FT100 returns

FTD $(-1)$ : FT.100 returns at $t-1$

COM: Commerzbank returns

MA (1): Moving average parameter order 1

Notes: The table entries are the estimated values of the coefficients for the model at equation (1.), with $t$-values shown underneath in parenthesis.

$t$-statistics computed using White's (1980) heteroscedasticity-consistent covariance matrix.

${ }^{8}$ All series showed abnormally low values from 19-22 August 1991. This could be related with the events surrounding the kidnapping suffered by Mr Gorbachov. We performed the analysis both with original data and with optimally interpolated data. The results were not very different, but we choose to use the data free of these abnormal values. 
analysing the multivariate relationships with the volatilities of the other foreign markets considered.

Table 5 shows several sample moments of the residuals from the regression model (1) fitted to the SSE returns. Comparing Tables 3 and 5, we observe that, in general, the skewness and kurtosis of the residuals are smaller than in the original index, but still significant. The McLeod-Li statistic, $\mathrm{Q}_{2}$, is still highly significant in the second and last regimes. However, if in the second subsample we compute $\mathrm{Q}_{2}$ without the first 50 observations, it takes an approximated value of 13. The first part of the second regime is highly influenced by the effects of the big crash beyond the two weeks we deleted and, therefore, the heteroscedasticity in this regime appears to be caused mainly by the crash. We also observe that the $Q_{3}$ statistics are not significant ${ }^{9}$ meaning that there are no significant 'leverage' effects in the data. Given that only the returns during the last regime have autocorrelations in the second moments, we only fit the ARV(1) model to the residuals from model (1) in the last subsample.

The estimation results of the ARV(1) model in (2) with day-of-the-week effects appear in the first column of Table 6 . We observe that the estimate $\phi \approx 0.9$ implies high persistence of volatility. The results for the SSE returns imply that the unconditional variance of Mondays is greater than the variance of the other week-days. We also estimate model (3) with asymmetric effects. The estimates of the asymmetric effects with two lags in the ARV(1) model, i.e. $\alpha_{i}$ in model (3), are not significant and therefore we do not report them. This is not surprising given the previous results for $\mathrm{Q}_{3}$ in Table 3 .

With respect to the diagnostics of the estimated model, we used smoothed estimates of volatility, $\mathrm{e}^{*}{ }_{t}=e_{t} / \hat{\sigma}_{t^{*}}$. The results in Table 6 are based on the standardized observations trimmed when the corresponding $e^{*}{ }_{t}$ is greater than three times the standard deviation. ${ }^{10}$ In Fig. 1 we represent the estimated density ${ }^{11}$ of the residuals standardized using the volatility implied by the ARV model together with the normal density. We observe that the ARV density is quite close to the normal, confirming the results for the skewness and kurtosis of the standardized observations in Table 6 , which are not significantly different from the values of the normal density. Looking at the McLeod-Li statistic, $\mathrm{Q}_{2}(10)$, the model seems to be successful in taking account of the autocorrelation present in the squared residuals from model (1). The second part of Table 6 shows the estimated parameters and coefficient of determination of the following regression

$$
y_{t}^{2}=a+b \hat{\sigma}_{t / T}^{2}+u_{t}
$$

as proposed by Pagan and Schwert (1990). If the estimates of volatility are unbiased then $a=0$ and $b=1$. If the residuals of this regression, $\hat{u}_{t}$, are

${ }^{9} \mathrm{The} \mathrm{Q}_{3}$ statistic is the sample correlation between $y_{t}$ and $y_{t-h}^{2}$. For $h>0$, this is a test for asymmetric effects.

${ }^{10}$ The trimming was carried out to get rid of two extreme observations at the end of the sample period.

${ }^{11}$ We are very grateful to M. Delgado and C. del Río for providing us with the subroutines needed to compute the density. 
autocorrelated, then there are additional dynamics in volatility that are not captured by the corresponding model. Looking at the estimates of (5) in Table 6 , we observe that the ARV model has a good fit between squared residuals and

Table 5. Sample moments of residuals from the regression model, equation (1)

\begin{tabular}{|c|c|c|c|c|}
\hline & \multicolumn{4}{|l|}{ Period } \\
\hline & $\begin{array}{l}1 / 1 / 87- \\
8 / 10 / 87 \\
\end{array}$ & $\begin{array}{l}28 / 10 / 87- \\
1 / 4 / 89\end{array}$ & $\begin{array}{l}2 / 4 / 89- \\
30 / 3 / 90\end{array}$ & $\begin{array}{l}31 / 3 / 90- \\
2 / 10 / 92\end{array}$ \\
\hline Mean & 0.0930 & -0.0093 & -0.0458 & -0.0284 \\
\hline Variance & 1.5904 & 0.8453 & 0.1726 & 0.6911 \\
\hline Skewness $^{a}$ & $\begin{array}{l}0.4746 \\
(7.09)\end{array}$ & $\begin{array}{l}-0.7150 \\
(28.46)\end{array}$ & $\begin{array}{l}0.2022 \\
(1.65)\end{array}$ & $\begin{array}{c}-0.2735 \\
(7.07)\end{array}$ \\
\hline Kurtosis $^{b}$ & $\begin{array}{l}5.0933 \\
(34.51)\end{array}$ & $\begin{array}{c}14.2936 \\
(1774.99)\end{array}$ & $\begin{array}{l}3.2500 \\
(0.63)\end{array}$ & $\begin{array}{c}5.4332 \\
(139.88)\end{array}$ \\
\hline Acf $^{\circ}$ & & & & \\
\hline$r(1)$ & $\begin{array}{l}0.0692 \\
(0.92)\end{array}$ & $\begin{array}{l}-0.0664 \\
(1.48)\end{array}$ & $\begin{array}{l}0.0444 \\
(0.48)\end{array}$ & $\begin{array}{l}0.0337 \\
(0.65)\end{array}$ \\
\hline r(2) & $\begin{array}{l}-0.0987 \\
(2.80)\end{array}$ & $\begin{array}{l}-0.0681 \\
(3.05)\end{array}$ & $\begin{array}{l}0.0789 \\
(2.02)\end{array}$ & $\begin{array}{l}0.0509 \\
(2.13)\end{array}$ \\
\hline$r(3)$ & $\begin{array}{l}-0.0493 \\
(3.27)\end{array}$ & $\begin{array}{l}-0.0315 \\
(3.39)\end{array}$ & $\begin{array}{l}0.0402 \\
(2.41)\end{array}$ & $\begin{array}{l}0.0056 \\
(2.14)\end{array}$ \\
\hline r(4) & $\begin{array}{l}0.0827 \\
(4.61)\end{array}$ & $\begin{array}{l}-0.0416 \\
(3.98)\end{array}$ & $\begin{array}{l}0.0171 \\
(2.49)\end{array}$ & $\begin{array}{l}0.0267 \\
(2.55)\end{array}$ \\
\hline$r(5)$ & $\begin{array}{l}0.0451 \\
(5.01)\end{array}$ & $\begin{array}{l}0.0045 \\
(3.98)\end{array}$ & $\begin{array}{l}0.0459 \\
(3.01)\end{array}$ & $\begin{array}{l}0.0494 \\
(3.95)\end{array}$ \\
\hline $\begin{array}{l}\mathrm{Q}(10) \\
\text { Acf squares }\end{array}$ & 10.97 & 8.39 & 6.47 & 7.91 \\
\hline$r_{2}(1)$ & $\begin{array}{l}0.0813 \\
(1.27)\end{array}$ & $\begin{array}{c}0.2267 \\
(17.32)\end{array}$ & $\begin{array}{l}-0.0249 \\
(0.15)\end{array}$ & $\begin{array}{l}0.1618 \\
(14.92)\end{array}$ \\
\hline$r_{2}(2)$ & $\begin{array}{l}-0.0546 \\
(1.84)\end{array}$ & $\begin{array}{c}0.3313 \\
(54.41)\end{array}$ & $\begin{array}{l}0.0225 \\
(0.28)\end{array}$ & $\begin{array}{l}0.1182 \\
(22.89)\end{array}$ \\
\hline$r_{2}(3)$ & $\begin{array}{l}0.1039 \\
(3.94)\end{array}$ & $\begin{array}{l}0.0716 \\
(56.15)\end{array}$ & $\begin{array}{l}-0.0013 \\
(0.28)\end{array}$ & $\begin{array}{l}0.0715 \\
(25.81)\end{array}$ \\
\hline$r_{2}(4)$ & $\begin{array}{l}0.0382 \\
(4.22)\end{array}$ & $\begin{array}{c}0.0491 \\
(56.97)\end{array}$ & $\begin{array}{l}-0.0719 \\
(1.56)\end{array}$ & $\begin{array}{c}0.1062 \\
(32.28)\end{array}$ \\
\hline$r_{2}(5)$ & $\begin{array}{l}0.0299 \\
(4.40)\end{array}$ & $\begin{array}{l}0.1113 \\
(61.20)\end{array}$ & $\begin{array}{l}-0.0588 \\
(2.42)\end{array}$ & $\begin{array}{l}0.2432 \\
(66.23)\end{array}$ \\
\hline $\begin{array}{l}Q_{2}(10) \\
y_{t} y_{T-T}^{2}\end{array}$ & 14.78 & 65.61 & 3.89 & 69.63 \\
\hline $\begin{array}{l}Q_{3}(1) \\
Q_{3}(2)\end{array}$ & $\begin{array}{l}-0.1459 \\
-0.0073\end{array}$ & $\begin{array}{l}0.1475 \\
0.2796\end{array}$ & $\begin{array}{r}0.0118 \\
-0.0377\end{array}$ & $\begin{array}{l}0.0354 \\
0.0070\end{array}$ \\
\hline$Q_{3}(5)$ & -0.1492 & 0.1000 & 0.0498 & -0.0614 \\
\hline
\end{tabular}

a The statistic in parenthesis has a $\chi^{2}{ }_{(1)}$ distribution under the null of zero skewness.

${ }^{b}$ The statistic in parenthesis has a $\chi_{(1)}^{2}$ distribution under the null of kurtosis $=3$.

'The values in parenthesis in the autocorrelation function (acf) and acf of squares are the BoxLjung statistics.

All returns were converted to percentages.

$Q(10)$ is the Ljung Box Statistic. 
the estimated conditional variances. Finally, the Box-Ljung statistic for 10 lags, of the residuals of these regressions are not significant.

Consequently, we adopt the ARV(1) model (4) for the volatility of the residuals of the SSE. We fit the same model for all market's volatilities. The estimation results also appear in Table 6 , where we observe that the autoregressive parameter of the log-volatility process is close to unity for all indexes considered, implying high persistence in variance. For all returns, except FTD, the standardized observations have excess kurtosis, i.e. the distribution of $\varepsilon_{t}$ in (2) seems to have heavier tails than normal. However, the McLeod-Li statistics are not significant for any of the returns.

Table 6. Estimation results of the ARV(1) models for sub-sample period 3

\begin{tabular}{|c|c|c|c|c|c|}
\hline & $\begin{array}{l}\text { SSE } \\
\text { Residuals }\end{array}$ & $D J$ & $C O M$ & FTD & NIK \\
\hline$\phi$ & $\begin{array}{c}0.8991 \\
(0.0800)\end{array}$ & $\begin{array}{c}0.9859 \\
(0.0103)\end{array}$ & $\begin{array}{c}0.9835 \\
(0.0184)\end{array}$ & $\begin{array}{c}0.9737 \\
(0.0168)\end{array}$ & $\begin{array}{c}0.9670 \\
(0.0257)\end{array}$ \\
\hline$\sigma_{\eta}^{2}$ & $\begin{array}{c}0.0791 \\
(0.0884)\end{array}$ & $\begin{array}{c}0.0438 \\
(0.0270)\end{array}$ & $\begin{array}{c}0.0302 \\
(0.0197)\end{array}$ & $\begin{array}{c}0.0422 \\
(0.0273)\end{array}$ & $\begin{array}{c}0.0339 \\
(0.0316)\end{array}$ \\
\hline$\sigma_{\xi}^{2}$ & $\begin{array}{c}4.4887 \\
(0.5398)\end{array}$ & $\begin{array}{c}7.9480 \\
(0.7667)\end{array}$ & $\begin{array}{c}5.5368 \\
(0.5396)\end{array}$ & $\begin{array}{c}4.9777 \\
(0.5209)\end{array}$ & $\begin{array}{c}6.3814 \\
(0.5803)\end{array}$ \\
\hline$\sigma_{(1)}^{2}$ & $\begin{array}{c}6.09 \times 10^{-5} \\
\left(5.68 \times 10^{-6}\right)\end{array}$ & $\begin{array}{c}1.88 \times 10^{-5} \\
\left(1.75 \times 10^{-6}\right)\end{array}$ & $\begin{array}{r}1.12 \times 10^{-4} \\
\left(1.04 \times 10^{-5}\right)\end{array}$ & $\begin{array}{c}8.04 \times 10^{-5} \\
\left(7.50 \times 10^{-6}\right)\end{array}$ & $\begin{array}{r}3.18 \times 10^{-4} \\
\left(2.97 \times 10^{-5}\right)\end{array}$ \\
\hline$\sigma_{(2)}^{2}$ & $\begin{array}{c}5.14 \times 10^{-5} \\
\left(4.79 \times 10^{-6}\right)\end{array}$ & $\begin{array}{c}2.09 \times 10^{-5} \\
\left(1.95 \times 10^{-6}\right)\end{array}$ & $\begin{array}{c}9.13 \times 10^{-5} \\
\left(8.51 \times 10^{-6}\right)\end{array}$ & $\begin{array}{c}8.57 \times 10^{-5} \\
\left(7.99 \times 10^{-6}\right)\end{array}$ & $\begin{array}{l}2.40 \times 10^{-4} \\
\left(7.12 \times 10^{-5}\right)\end{array}$ \\
\hline $\begin{array}{l}\log L \\
e^{*}\end{array}$ & -728.86 & -889.05 & -785.87 & -742.25 & -822.58 \\
\hline Mean & -0.0017 & -0.0072 & 0.0341 & -0.0030 & 0.0130 \\
\hline Variance & 1.0003 & 1.0001 & 1.0058 & 1.0000 & 1.0001 \\
\hline Skewness ${ }^{a}$ & $\begin{array}{l}-0.0937 \\
(0.83)\end{array}$ & $\begin{array}{l}0.1235 \\
(1.44)\end{array}$ & $\begin{array}{l}0.1717 \\
(2.78)\end{array}$ & $\begin{array}{l}0.2228 \\
(4.69)\end{array}$ & $\begin{array}{l}0.2058 \\
(4.0)\end{array}$ \\
\hline Kurtosis ${ }^{b}$ & $\begin{array}{l}3.0483 \\
(0.06)\end{array}$ & $\begin{array}{c}6.3361 \\
(262.93)\end{array}$ & $\begin{array}{l}3.5416 \\
(6.93)\end{array}$ & $\begin{array}{l}3.3475 \\
(2.85)\end{array}$ & $\begin{array}{l}3.6243 \\
(9.21)\end{array}$ \\
\hline $\begin{array}{l}Q_{2}(10) \\
\text { Regression }\end{array}$ & 6.80 & 7.67 & 13.50 & 13.06 & 14.28 \\
\hline a & $\begin{array}{l}-0.0001 \\
\left(2.63 \times 10^{-6}\right)\end{array}$ & $\begin{array}{r}-6.97 \times 10^{-6} \\
\left(1.68 \times 10^{-6}\right)\end{array}$ & $\begin{array}{c}-2.69 \times 10^{-6} \\
\left(2.58 \times 10^{-13}\right)\end{array}$ & $\begin{array}{l}-0.0001 \\
\left(4.11 \times 10^{-6}\right)\end{array}$ & $\begin{array}{l}-0.0001 \\
\left(1.49 \times 10^{-5}\right)\end{array}$ \\
\hline$b$ & $\begin{array}{l}2.3552 \\
(0.042)\end{array}$ & $\begin{array}{l}1.2015 \\
(0.042)\end{array}$ & $\begin{array}{l}1.0454 \\
(0.042)\end{array}$ & $\begin{array}{l}1.6822 \\
(0.042)\end{array}$ & $\begin{array}{l}1.3825 \\
(0.042)\end{array}$ \\
\hline$R^{2}$ & 0.2193 & 0.0822 & 0.1802 & 0.1069 & 0.1622 \\
\hline$Q(10)$ & 10.67 & 18.07 & 8.03 & 18.69 & 22.87 \\
\hline
\end{tabular}

a The statistic in parenthesis has a $\chi_{(1)}^{2}$ distribution under the null of zero skewness.

b The statistic in parenthesis has a $\chi_{(1)}^{2}$ distribution under the null of kurtosis $=3$.

c The regression was proposed by Pagan and Schwert (1990) and is given by:

$y_{t}^{2}=a+b \hat{\sigma}_{t / T}^{2}+u_{t}$

Under the null, $a=0, b=1$.

All returns were converted to percentages.

The table also shows the results of fitting the ARV(1) model to the four foreign markets. 


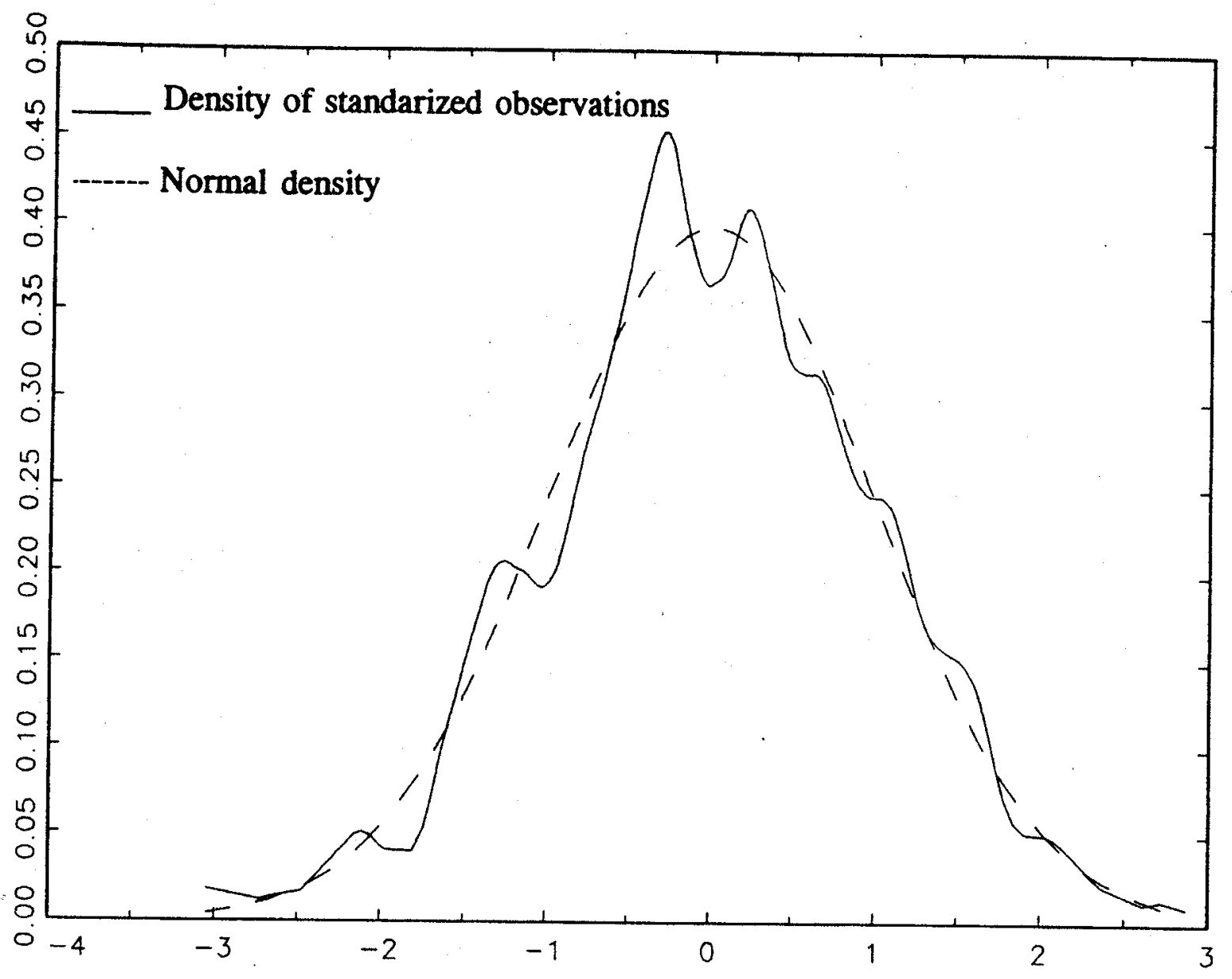

Fig. 1. Fitted empirical density of standardized estimated volatilities Note: The mean and variance of the normal distribution are equal to the sample mean and variance, respectively of the empirical distribution.

Figure 2 represents the smoothed estimates of volatility for each index. Looking at the smoothed estimates in the different markets, we observe that it seems that there are common movements in volatility, specially when the markets have high volatility. This fact has also been observed by other authors (Aderhold et al., 1988 and Furstenberg and Jeon, 1989).

To analyse the possible relationship between the volatility in SSE and the international volatilities we computed the correlation matrix between the smoothed estimates of volatility, which is given by

\begin{tabular}{|c|c|c|c|c|c|}
\hline & SSE & DJ & COM & FTD & NIK \\
\hline \multirow{3}{*}{$\Sigma=$} & 1. & 0.3025 & 0.1146 & 0.1890 & 0.1695 \\
\hline & & 1. & 0.3643 & 0.3336 & 0.5110 \\
\hline & & & 1. & -0.1368 & 0.3138 \\
\hline
\end{tabular}

Looking at matrix $\sum$, it seems that after discounting the international effects on the conditional mean, the conditional variance of SSE is mainly related to DJ 


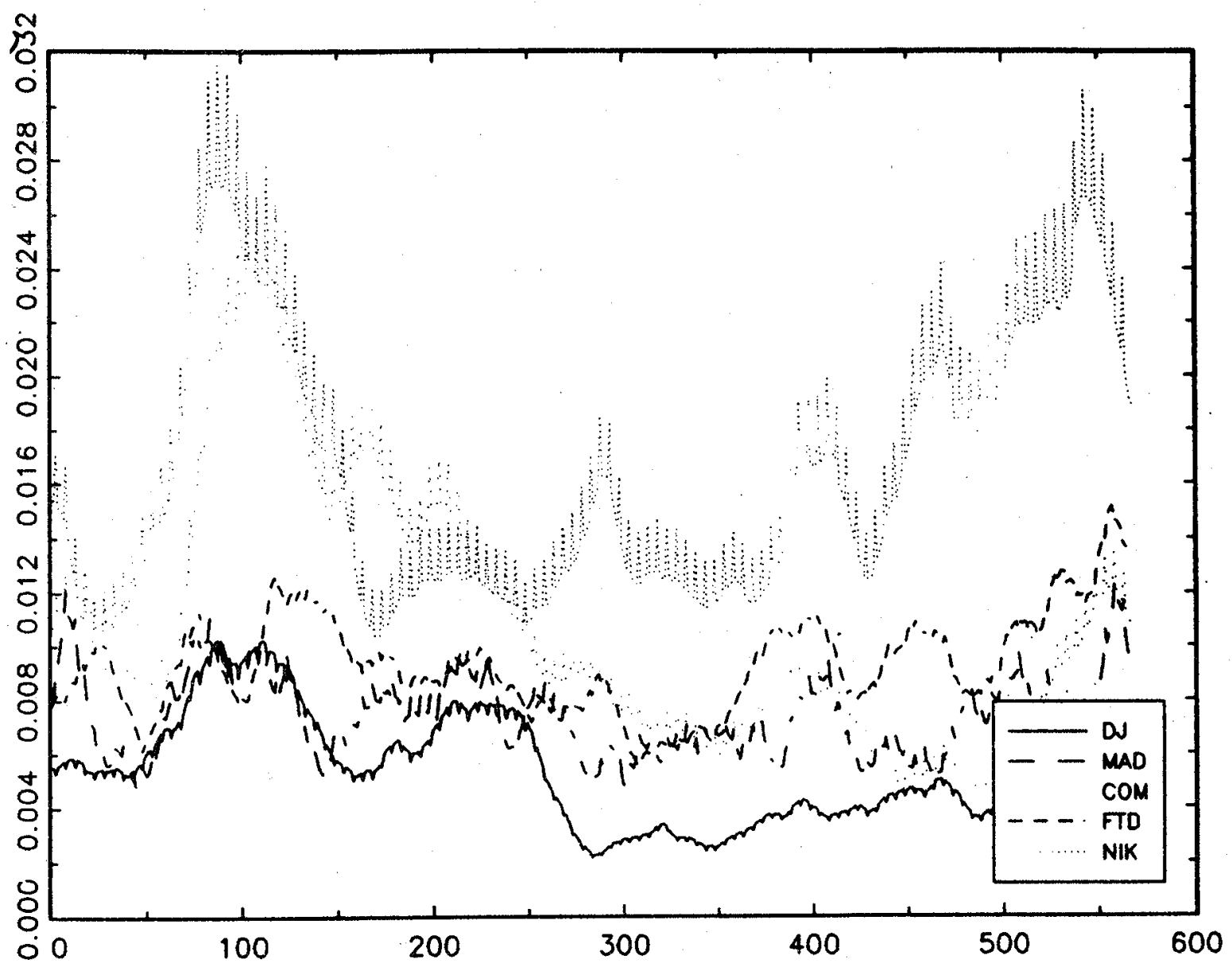

Fig. 2. Smoothed estimates of volatility for the five markets in the study

(New York) volatility, although it has also relationships with the other markets. A principal component analysis of the correlation matrix reveals that with one component it is possible to explain approximately $40 \%$ of the variability in the volatilities and that with two components we may explain $64 \%$ of the variability. The weights of each volatility on these two components are given by

First component Second component

\begin{tabular}{llr}
\hline SSE & 0.5171 & 0.2865 \\
DJ & 0.8575 & 0.0361 \\
COM & 0.5397 & -0.6772 \\
FTD & 0.4138 & 0.7727 \\
NIK & 0.7445 & -0.1790
\end{tabular}

The first component may be interpreted as a 'world' underlying volatility with NYSE having the greatest weight. The second component is mostly 
'European', with Frankfurt and London as the dominant factors, albeit with opposite signs. ${ }^{12}$

\section{CONCLUSIONS}

The present analysis suggests a growing influence of the main world stock markets on the SSE. Although the main relevant markets are New York, London and Frankfurt, it is worth noting that New York seems to be the most influential market on the SSE both in mean and in variance. In the case of the conditional mean, this influence was first realized around the October 1987 meltdown and has got stronger since, specially when the Continuous Market system is working. Thus, the reforms seem to have improved operational efficiency and also acted as a catalyst of international financial integration. The joint effect of those markets could perhaps be interpreted as one equation in the single factor world capital asset pricing model of Harvey and Zhou (1993). However, in spite of the increased integration with other markets, the idiosyncratic component of the SSE mean return is still higher than $50 \%$ of the total. This suggests that valuable diversification gains for investing in the SSE may still be relevant.

Future research will include expansion of the model in the line of multivariate SV models. In fact, the principal components analysis of the previous section suggests that it could be worth trying to estimate a multivariate model for volatility as in Harvey et al. (1994) and this is left for future research. Other lines of research include trading simulations to check if the (risk-adjusted) excess profits that the model could generate, vanish when transaction costs and taxes are included. Measures for risk-free rates could be of the same form as Solnik (1993) who uses one-month Euro-currency interest rates or, alternatively, we could use daily interbank offer rates. Additionally, we could use the models for volatility to price derivatives on the SSE index, especially options.

\section{ACKNOWLEDGEMENTS}

The authors acknowledge financial support from the Applied Econometrics Programme of the Argentaria Chair at the University Carlos III de Madrid and from DGICYT grants PB92-0244 and PB93-0234. Also, we are grateful to E. Morales and D. Manzano for providing some data and to two anonymous referees for many detailed comments which have helped to improve the paper. Earlier versions of this paper were presented in seminars at Universidad Complutense, Universidad del Pais Vasco, Universidad Carlos III and Chemical Bank-Imperial College Conference on Forecasting Financial Markets.

\section{REFERENCES}

Aderhold, R., Cumming, C. and Harwood, A. (1988) International linkages among equities markets and the October 1987 market break, Federal Reserve Bank of New York Quarterly Review, 13, 33-46.

\footnotetext{
${ }^{12}$ As suggested by an anonymous referee, other interpretations of the second principal component are possible.
} 
Baillie, R.T. and Bollerslev T. (1989) The message in daily exchange rates: a conditionalvariance tale, J. Business and Economic Statistics, 7, 297-305.

Becker, K.G., Finnerty, J.E. and Gupta, M. (1990) The intertemporal relation between the U.S. and Japanese stock markets, J. Finance, 45, 1297-306.

Black, F. (1976) Studies in stock price volatility changes, Proceedings of the 1976 Business Meeting of the Business and Economic Statistics Section, ASA, pp. 177-81.

Christie, A. (1982) The stochastic behavior of common stock variances, J. Financial Economics, 10, 407-32.

Dunsmuir, W. (1979) A central limit theorem for parameter estimation in stationary vector time series and its applications to models for a signal observed with noise, Ann. Statistics, 7, 490-506.

Espitia, M. and Santamaría, R. (1991) Interacción Internacional entre Mercados de Valores, Información Comercial Española, 689, 518-31.

Eun, C.S. and Shim, S. (1989) International transmission of stock market movements, $J$. Financial and Quantitative Analysis, 24, 241-56.

French, K. and Poterba, I. (1990) Are Japanese stock prices too high? N.B.E.R. Summer Institute.

Furstenberg, G. and Jeon, B. (1989) International stock price movements: links and messages, Brookings Papers on Economic Activity, 1, 125-79.

Hamao, Y., Masulis, R.W. and Ng, V. (1990) Correlations in price changes and volatility across international stock markets, Rev. Financial Studies, 3, 281-307.

Harvey, C.R. and Zhou, G. (1993) International asset pricing with alternative distributional specifications, J. Empirical Finance, 1, 107-31.

Harvey, A.C., Ruiz, E. and Shephard, N.G. (1994) Multivariate stochastic variance models, $R$. Economic Studies, 61, 247-64.

Harvey, A.C. and Shephard, N.G. (1993) Estimation and testing of stochastic variance models. STICERD discussion papers, no. EM/93/268, London School of Economics.

Hsieh, D. (1989) Modeling heteroscedasticity in daily foreign-exchange rates, J. Business and Economic Statistics, 7, 307-17.

Lo, A.W. and MacKinlay, A.C. (1990) An economic analysis of nonsynchronous trading, $J$. Econometrics, 45, 181-211.

Manzano, D. and Mateos, B. (1991) Los Principales Mercados Bursátiles tras el Crash de 1987: Comportamiento e Interrelación, Papeles de la Economía Española, 34, 458-74.

Nelson, D.B. (1988) The time series behavior of stock market volatility and returns. Unpublished $\mathrm{Ph} \mathrm{D}$ dissertation, Massachusetts Institute of Technology.

Nelson, D.B. (1991) Conditional heteroscedasticity in asset returns: a new approach, Econometrica, 59, 347-70.

Pagan, A. and Schwert, G. (1990) Alternative models for conditional stock volatility, $J$. Econometrics, 45, 267-90.

Peña, J.I. (1992a) Sobre la Relación entre los Mercados Bursátiles Internacionales y la Bolsa de Madrid, Información Comercial Español, 704, 16-24.

Peña, J.I. (1992b) On meteor showers in stock markets, Investigaciones Economicas, 16, 225-34.

Peña, J.I. (1995) Stock market microstructure in Spain: a note, International Journal of Management, in press.

Ruiz, E. (1994) Quasi-maximum likelihood estimation of stochastic variance models, $J$. Econometrics, 63, 289-306.

Scholes, M. and Williams, J. (1977) Estimating betas from nonsynchronous data, $J$. Financial Economics, 5, 309-27. 
Solnik, B. (1993) International asset allocation strategies, J. Empirical Finance, 1, 33-56.

Taylor, S.J. (1986) Modelling Financial Time Series, Chichester: John Wiley.

White, H. (1980) A heteroscedastic-consistent covariance matrix estimates and a direct test for heteroscedasticity, Econometrica, 48, 817-38. 